DOI: $\underline{\text { https://doi.org/10.24867/15CG01Tepavac }}$

\title{
SAOBRAĆAJNE POVRŠINE SA PRATEĆOM INFRASTRUKTUROM U ULICI LAZE NANČIĆA, DELU BULEVARA EVROPE I NOVOPLANIRANOJ ULICI U NOVOM SADU
}

\section{TRAFFIC AREAS WITH ACCOMPANYING INFRASTRUCTURE ON LAZE NANČIĆA STREET, PART OF EUROPE BOULEVARD AND NEWLY PLANNED STREET IN NOVI SAD}

\author{
Milica Tepavac, Bojan Matić, Fakultet tehničkih nauka, Novi Sad
}

\section{Oblast - GRAĐEVINARSTVO}

Kratak sadržaj - Ovim radom obuhvaćen je proces terenskog $i$ laboratorijskog ispitivanja, sa analizom rezultata na osnovu koga je sproveden kompletan tok projektovanja saobraćajnica $i$ pratećih površina u ulici Laze Nančića, delu Bulevara Evrope, i novoplaniranoj ulici sa vezom do Bulevara Evrope u Novom Sadu- sa dimenzionisanjem $i$ usvajanjem kolovozne konstrukcije prema standardu SRPS U C4.015

Ključne reči: Ispitivanje, projektovanje, dimenzionisanje kolovozne konstrukcije, nova gradnja

Abstract - This project includes a process of field and laboratory testing, with an analysis of the results based on when the complete course of designing roads and ancillary areas in Laza Nančića Street, part of Boulevard of Europe, and the newly planned street with a connection to Boulevard of Europe in Novi Sad - with sizing and adoption pavement structures according to the standard SRPS U C4.015

Keywords: Examination, design, dimensioning of road construction, new construction

\section{UVOD}

Pravilan razvoj i funkcionisanje jedne države je nemoguće uspostaviti bez prateće infrastrukture. Putna mreža kao jedan od elemenata saobraćajne infrastrukture je direktan pokazatelj stepena razvoja i kao takva mora da ima definisana pravila pod kojima je upravljač može staviti u upotrebu, ali i pravila namenjena korisnicima [1]. Formiranje saobraćajne osnove urbanog područja kao i njeno prostorno i funkcionalno usklađivanje sa gradskim organizmom suštinski je sadržaj urbanističkih planova višeg reda (Generalni urbanistički plan, Plan generalne regulacije) i/ili Generalnog plana razvoja saobraćaja koji je ključna baza urbanističkog plana. Istovremeno saobraćajna osnova postojećeg stanja je takođe neophodan dokument kako sa stanovišta planiranja tako i sa stanovišta operativnih mera upravljanja gradskim saobraćajem [2] .

Na uglu ulica Bulevar Evrope i Laze Nančića, na teritoriji grada Novog Sada, gledano ka ulici Cara Dušana, sa desne strane u toku je gradnja stambenog kompleksa čiji je investitor „Dijagoninvest“", kao i sa leve strane, čiji je investitor „Rapid invest“ čiji sadržaj je namenjen opštegradskom i prigradskom centru.

\section{NAPOMENA:}

Ovaj rad proistekao je iz master rada čiji mentor je bio dr Bojan Matić, vanr.prof.
Kako bi se obezbedili svi preduslovi za normalno funkcionisanje ovih stambenih objekata, i omogućio pristup istim, zahteva se dodatna potrebna infrastrukturna oprema $u$ okviru okoga kompleksa.

Pored tih zahteva, predviđena je izgradnja saobraćajnih površina različite namene duž ulice Laze Nančića, od Bulevara Evrope do Cara Dušana, kako bi se ostvarila nova funckionalna saobraćajna celina u ovom delu grada.

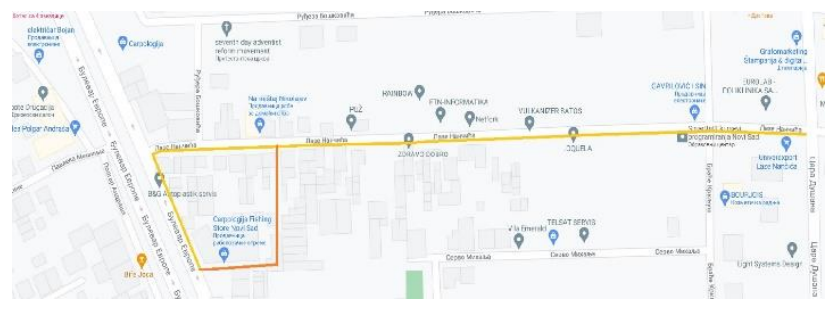

Slika 1. Pregledna karta obuhvata predmetnih ulica [3]

\section{SITUACIONO REŠENJE NOVOPLANIRANE SAOBRAĆAJNE INFRASTRUKTURE}

\subsection{Ulica Laze Nančića}

Saobraćajnica ulice Laze Nančića biće prema urbanističkim propisima sužena na $5 \mathrm{~m}$, tako da osovina novoprojektovanog puta prati osovinu postojećeg, odnosno obostrano će se suziti kolovoz za $0,5 \mathrm{~m}$.

Prema svom funkcionalnom rangu je sabirna ulica, sa usvojenom računskom brzinom od $\mathrm{Vr}=50 \mathrm{~km} / \mathrm{h}$, bez prelaznica, sa graničnim elementima plana i podužnog profila:

- Teren - ravničarski

- $\mathrm{Vr}=50 \mathrm{~km} / \mathrm{h}$

- Min radijus horizontalne krivine, $\min \mathrm{R}=50(30) \mathrm{m}$

- Minimalni radijusi vertikalne krivine:

- konveksno zaobljenje, min Rkonv=2000m

- konkavno zaobljenje min Rkonk=800m

- Maksimalni podužni nagib, $\max$ in=7\%

- Poprečni nagibi, ipop=2.5\% (2.0\%), $\max$ ipop $=4.0 \%$

$\mathrm{Na}$ početku osovina je uklopljena u postojeće stanje, na kotu nivelete Bulevara Evrope.Formirana je lepeza na raskrsnici sa bulevarom, sa radijusima $R=14 \mathrm{~m}$ (izlivni) $i$ $\mathrm{R}=8 \mathrm{~m}$ (ulivni). Na kraju je uklopljena u postojeće stanje na kotu nivelete ulice Cara Dušana, sa oblikovanom lepezom, radijusa $\mathrm{R}=8 \mathrm{~m}$ i $\mathrm{R}=10 \mathrm{~m}$, koji prate prvobitno geometrijsko rešenje. Dužina ukupne projektovane ose ulice Laze Nančića iznosi 581,58 m.

U ovoj ulici, projektovano je ukupno 46 kolskih ulaza u širini od $3.50 \mathrm{~m}$, sa završnom obradom od behaton ploča. Zbog tendencije da se u ovoj ulici smanji brzina kretanja 
automobila, na ovoj raskrsnici predviđa se platforma za usporenje saobraćaja, na delu biciklističkog i pešačkog prelaza, vidu izdignute paltforme.

Platforme imaju navoznu površinu nagiba $10 \%$, i kompletna platforma predviđena je sa završnom obradom od behaton ploča, sa dimenzijama i karakterstikama usvojenim spram saobraćajnog opterećenja. Pešački prelazi projektovani su u širini od $3.0 \mathrm{~m}$, a biciklistički širine $2,00 \mathrm{~m}$.

Raskrsnica je sa ulicom Braće Krkljuš- obrađena četvorokraka raskrsnica, sa lepezama radijusa $\mathrm{R}=6 \mathrm{~m}$, gde je formirana četvorokraka paltforma, sa navoznim površinama nagiba $10 \%$, sa završnom obradom od behaton ploča.

Nakon ove raskrsnice, saobraćajnica se proširuje do raskrsnice sa ulicom Cara Dušana, gde se formira širina saobraćajnice od 9m, tačnije formiraju se tri saobraćajne trake od po $3 \mathrm{~m}$. Dve saobraćajne trake za tekući smer, i jedna za suprotan smer od vođenja osovine.

\subsection{Novi krak ulice od Laze Nančića do produžetka ulice Servo Mihalja, koja se spaja sa Bulevarom Evrope}

Novi krak ulice projektovan je sa istočne i južne strane planiranog kompleksa zgrada Dijagonale, situaciono posmatrano- paralelno sa Bulevarom Evrope. Formirana je osovina „NOVA ULICA“ i ,SERVO MIHALjA“. Šrine ovih ulica se predviđaju od $5.0 \mathrm{~m}$, dvosmerne i seku se pod pravim uglom.

Prema svom funkcionalnom rangu se klasifikuju kao pristupne ulice, sa usvojenom računskom brzinom od $\mathrm{Vr}=30 \mathrm{~km} / \mathrm{h}$, bez prelaznica, sa usvojenim graničnim elementima plana i podužnog profila:

- Teren - ravničarski

- $\mathrm{Vr}=30 \mathrm{~km} / \mathrm{h}$

- Minimalni radijus horizontalne krivine, $\min \mathrm{R}=25 \mathrm{~m}$

- Minimalni radijusi vertikalne krivine:

- konveksno zaobljenje, min Rkonv=250m

- konkavno zaobljenje, min Rkonk=100 (50)m

- Maksimalni podužni nagib, max in=10\%

- Poprečni nagibi: $\min$ ipop $=2.5 \%(2.0 \%)$, $\max$ ipop $=4.0 \%$

Prva osovina je osa_nova ulica, istočni krak- vođena u pravcu sever jug, u dužini od $96.96 \mathrm{~m}$. Na početku je uklopljena na kotu novoprojektovane nivelete ose Laze Nančića (stacionaža $0+107,85 \mathrm{~km}$ ), gde se formira trokraka raskrsnica bez kanalisanja i bez semaforske signalizacije. Radijusi koji formiraju lepezu sa ulicom Laze Nančića su $6 \mathrm{~m}$. Osa se na kraju priključuje na početak ose novog kraka, ka Bulevaru Evrope.

Drugi krak ulice projektovan je sa južne strane planiranog kompleksa zgrada Dijagonale. Na ovoj raskrsnici dozvoljeno je samo desno odnosno levo skretanje, jer ovim radom i projektom nije predviđeno potpuno spajanje i formiranje ulice Servo Mihalja. Osovina „ose_Servo Mihalja“, prema projektu, vođena u pravcu zapad-istok, u dužini od $67.51 \mathrm{~m}$.

Na početku je niveleta uklopljena na kotu nivelete Bulevara Evrope, (stacionaža ose B.Evrope je 0+025,46 km), dok je na kraju uklopljena na kotu nivelete ose nove ulice. Sa Bulevarom Evrope formira lepeze radijusa $R=8 \mathrm{~m}$ i $\mathrm{R}=10 \mathrm{~m}$.

\subsection{Parking prostor}

Severni parking: Projektovan na početku formirane ose Laze Nančića, sa desne strane ulice, posmatrano ka ulici Cara Dušana. Ukupno 23 upravna parking mesta,u širini od 2,5 m i dubini 4,6m. Od toga 1 mesto predviđeno za osobe sa invaliditetom u širini od $3,70 \mathrm{~m}$. Obezbeđen je prepust vozila i do $0,7 \mathrm{~m}$. Završna obrada ovoga parkinga predviđena je od raster ošupljenih ploča.

Dodatni parking: U ulici Laze Nančića, kod raskrsnice Cara Dušana se predviđa izgradnja parking prostora od 13 parking mesta, dubine $5 \mathrm{~m}$, i širine $2,5 \mathrm{~m}$, sa obezbeđenim prepustom za vozila. Obezbeđeno je jedno mesto za osobe sa invaliditetom, stacionirano najbliže raskrsnici, u širini od $3,70 \mathrm{~m}$. Parking ima direktnu vezu sa pešačkom stazom. Između parkinga, ostavljen je prostor za zelene površine. Završna obrada ovih parkinga predviđa se od ošupnjenih betonskih ploča, za koje se predviđa ispuna rizlom ili travom.

Zapadni parking: Parking uz desnu ivicu Bulevara Evrope- projektovan je kosi parking pod uglom od 45 stepeni. Ukupno 16 parking mesta, od toga 2 parking mesta za osobe sa invaliditetom, širine $3,70 \mathrm{~m}$, na mestima najbližim raskrsnici i ulazu u objekat. Širina parkinga iznosi $2,50 \mathrm{~m}$, i upravnoj dubini od 4,6 m. Obezbeđene su bele prepust parking ploče $0.40 \mathrm{~m}$, uz gornju ivicu parkinga, do biciklističke staze. Završna obrada od punih betonskih ploča, tipa behaton.

Južni parking: Projektovan je upravno, sa desne protočne strane vozila uz novi krak ulice Servo Mihalja. Ukupan broj parking mesta je 11, od toga 1 parking mesto obezbeđeno za osobe sa invaliditetom, širine $3,70 \mathrm{~m}$. Parkinzi su širine $2,5 \mathrm{~m}$, dubine $4,6 \mathrm{~m}$, sa obezbeđenim prepustom za parkiranje vozila. Završna obrada ovih parkinga predviđena je od raster ošupljenih ploča.

\subsection{Biciklistička staza}

Biciklistička staza prati postojeću saobraćajnicu Bulevara Evrope i locirana je paralelno sa njene desne strane, fizički zaštićena od protočnog kolovoza. Dužina staze proteže se u dužini od oko $100 \mathrm{~m}$. Širina staze je 2,0m, čime se obogućava dvosmerni saobraćaj biciklista. Staza je u pravcu, bez horizontalnih krivina. Maksimalni podužni nagib na stazi ograničen je na $4 \%$. završna obrada predviđa se od asfaltnih slojeva.

\subsection{Pešačke staze}

Pešačke staze projektovane su u širini od najmanje $1.60 \mathrm{~m}$, što je neophodno za dvosmerno kretanje pešaka do širine na nekim mestima i do $5,5 \mathrm{~m}$, gde slobodan prostor dozvoljava, ovičena i fizički razdvojena od protočnog saobraćaja. Oko stambenog kompleksa projektovana je staza sa sve 4 strane. Širina staze je usvojena spram širine regulacije u datim ulicama. Duž ulice Laze Nančića, širina trotoara je $1,60 \mathrm{~m}$, bez prekida na kolskim ulazima, imajući u vidu prednost kretanja pešacima, s tim što se na tom delu predviđa ojačanje staze, $\mathrm{u}$ vidu betonskih kocki veće debljine, zbog prelaska saobraćajnog opterećenja. Šrina trotoara, uz zapadni ulaz, do Bulevara Evrope usvojena je na 3,00 m, obzirom da je tu protok pešaka veći, a i prati kontinuitet gradnje pešačkih staza na Bulevaru Evrope. 


\section{TERENSKA I LABORATORIJSKA ISPITIVANJA}

Projektna rešenja su data na osnovu terenskih istraživanja i laboratorijskih ispitivanja i karakteristika materijala $\mathrm{u}$ podtlu.

$\underline{\text { U okviru terenskih istraživanja izvedeno je: }}$

\section{Inženjersko-geološko kartiranje terena}

Inženjersko-geološkim kartiranjem je obuhvaćena površina od $\sim 6 h a$ u Novom Sadu u zoni istražne lokacije. Inženjersko-geološkim kartiranjem prikupljaju se podaci:

$>$ o reljefu, genezi i morfološkim oblicima;

$>$ o geodinamičkim procesima.

\section{Izvođenje istražnih jama}

Izvedeno je 4 (četiri) istražne jame. Istražne jame izvedene su ručno.

\section{Istražno bušenje}

U cilju definisanja litološkog sastava terena, prostornog položaja inženjersko+geoloških jedinica, merenja nivoa izdani i uzimanja uzoraka za laboratorijska ispitivanja fizičko-mehaničkih svojstava izvedene su 2 (dve) istražne bušotine, ukupne dubine $4.1 \mathrm{~m}$. Bušotine su izvedene ručno, stvrdlom.

Inženjersko-geološko kartiranje zidova jama i uzimanje uzoraka iz istražnih jama i bušotina za laboratorijska ispitivanja fizičko-mehaničkih svojstava

Uporedo sa izvođenjem istražnih jama izvedeno je i inženjersko-geološko kartiranje zidova istražnih jama. $\mathrm{Na}$ materijalu iz iskopa rađeni su terenski opiti (u zavisnosti od koherentnog stanja) za određivanje konzistentnih stanja, određivanje sadržaja sitnih frakcija, reakcija pri opitu trešenja, opit valjanja, opit čvrstoće tla u suvom stanju (opit lomljenja) i prisustvo organskih materija. Paralelno sa inženjersko-geološkim kartiranjem vršeno je uzimanje uzoraka za laboratorijska ispitivanja. Ukupno je za laboratorijska ispitavanja odabrano 4 (četiri) uzorka, iz istražnih jama i 2 (dva) uzorka iz istražnih bušotina

$\underline{\text { U okviru laboratorijskih ispitivanja izvedeno je: }}$

- određivanje granulometrijskog sastava tla SRPS U.B1. 018

- određivanje zapreminske mase sa porama SRPS U.B1. 013

- određivanje zapreminske mase bez pora SRPS U.B1. 014

- određivanje prirodne vlažnostiSRPS U.B1. 012

- karakteristike plastičnosti SRPS U.B1. 020

- Proktorov opit SRPS U.B1.038

- laboratorijski CBR opit SRPS EN 13286-47

Rezultati laboratorijskih i terenskih ispitivanja:

$\mathrm{Na}$ osnovu sinteze dokumentacionih i dopunskih istraživanja $i$ ispitivanja terena urađena je analiza rezultata i dati su geotehnički uslovi i preporuke za izgradnju saobraćajnih površina.

Tokom izvođenja istražnih radova nije uočena podzemna voda, i nije definisan njen nivo. Pretpostavlja se da na terenu postoji plitka izdan koja se prihranjuje atmosferskim padavinama.

Slojevi kolovozne konstrukcije postojeće saobraćajnice (kk) - U istražnim jamama IJ-1 i IJ-2 slojevi kolovozne konstrukcije predstavljeni su bitošljunkom debljine 10$11 \mathrm{~cm}$, drobljenim kamenim agregatom 0-31.5 mm debljine $32-33 \mathrm{~cm}$.

U istražnoj jami IJ-3 slojevi kolovozne konstrukcije predstavljeni su asfaltom debljine $5 \mathrm{~cm}$ i drobljenim kamenim agregatom $0-31.5 \mathrm{~mm}$ debljine $45 \mathrm{~cm}$. U istražnoj jami IJ-4 slojevi kolovozne konstrukcije predstavljeni su asfaltom debljine $4 \mathrm{~cm}$, starim asfaltom debljine $10 \mathrm{~cm}$, šljunkom debljine $12 \mathrm{~cm}$ i tlom sa šutom debljine $20 \mathrm{~cm}$.

Za izradu posteljice saobraćajnih površina mogu se upotrebiti materijali koji ispunjavaju zahteve standarda SRPS U.E8.010 (projektovanje i građenje puteva - nosivost i ravnost na nivou posteljice), prikazane su u tabeli broj 1 .

Tabela 1. Zahtevane vrednosti parametara za izradu posteljice

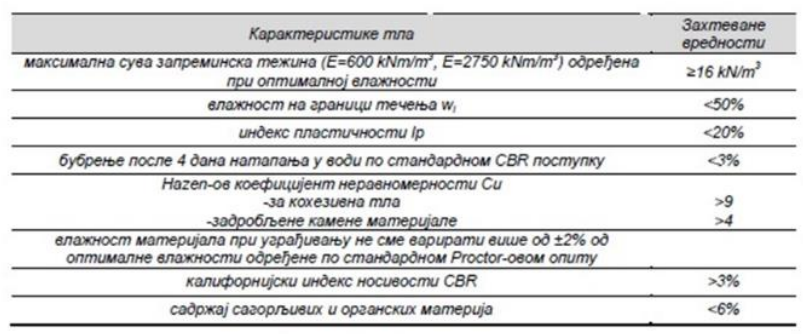

Prema Kasagrandeovom kriterijumu materijal na dubini do $0.8 \mathrm{~m}$, u istražnim jamama IJ-1, IJ-2, IJ-3 i IJ-4, nije otporan na dejstvo mraza. Imajući u vidu da je aktivna zona dejstva mraza u Novom Sadu do 70-90cm preporučuje se zamena tla posteljice celom dužinom trase projektovane saobraćajnice adekvatnim materijalom koji je otporan na dejstvo mraza.

$\mathrm{Na}$ osnovu rezultata dobijenih laboratorijskim ispitivanjem, prilikom dimenzionisanja kolvoozne konstrukcije preporuka je da se usvoji vrednost CBR-a 5.4\%

\section{KOLOVOZNA KONSTRUKCIJA}

Dimenzionisanje nove kolovozne konstrukcije se vrši prema standardu SRPS U.C4.015. Proračunom se određuju potrebne debljine slojeva kolovozne konstrukcije. Na osnovu rezultata i preporuke nakon analize laboratorijskih i terenskih ispitivnja, usvojena vrednost kalifornijskog indeksa nosivosti CBR iznosi: 5,40\%.

Potrebni strukturni broj SNpot, na osnovu standarda SRPS U.C4.015. prema AASHTO Guide for Design of pavement structures, određuje se na osnovu sledećih podataka:

Tabela 2. Vrednosti parametara na osnovu kojih se očitava potreban strukturni broj sa nomograma

\begin{tabular}{ll}
\hline Параметар & Вредност \\
\hline Саобраћајно оптерећење ЕСО & $1.35 \times 10^{6}$ ст. осов. 82 kN \\
\hline Поузданост R & $85 \%$ \\
\hline Стандардно нормално одступање Zr & -1.037 \\
\hline Стандардно одступање So & 0.40 \\
\hline Почетни индекс возне способности коловоза ро & 4.2 \\
\hline Крајњи индекс возне способности коловоза рt & 2.0 \\
\hline Резилијентни модул постељице Мr & $50 \mathrm{MPa}$ \\
\hline Потребан структурни број СНпот & $\mathbf{8 . 9} \mathbf{c m}$ \\
\hline
\end{tabular}


Predložena i usvojena šema kolovozne konstrukcije, koja prema ispunjava sve tehničke standarde po pitanju nosivosti nakon provere napona i deformacija, prema programskom paketu DAMA, data kolovozna konstrukcija je otporna po pitanju napona i deformacija i zadovoljena je po pitanju trajnosti i prikazana je na slici 2 . usvaja se vrednost od $30 \mathrm{~cm}$ zamene materijala $u$ posteljici nekim otpornim na dejstvo mraza. Projektovana vrednost strukturnog broja iznosi:

$\mathrm{Sn}^{\text {proj }}=\mathrm{d}_{\mathrm{ab} 11 \mathrm{~s}} * \mathrm{a}_{\mathrm{ab} 11 \mathrm{~s}}+\mathrm{d}_{\mathrm{bns} 22} * \mathrm{a}_{\mathrm{bns} 22}+\mathrm{d}_{\mathrm{dk} 0 / 31} * \mathrm{a}_{\mathrm{dk} 0 / 31} * \mathrm{~m}+$ $\mathrm{d}_{\mathrm{dk} 0 / 63} * \mathrm{a}_{\mathrm{dk} 0 / 63} * \mathrm{~m}$

$\mathrm{Sn}^{\mathrm{proj}}=5 * 0,42+8 * 0,36+1 * 15 * 0,14+1 * 0,12 * 20$

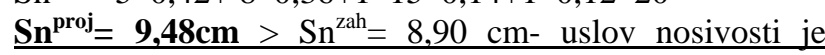
zadovoljen

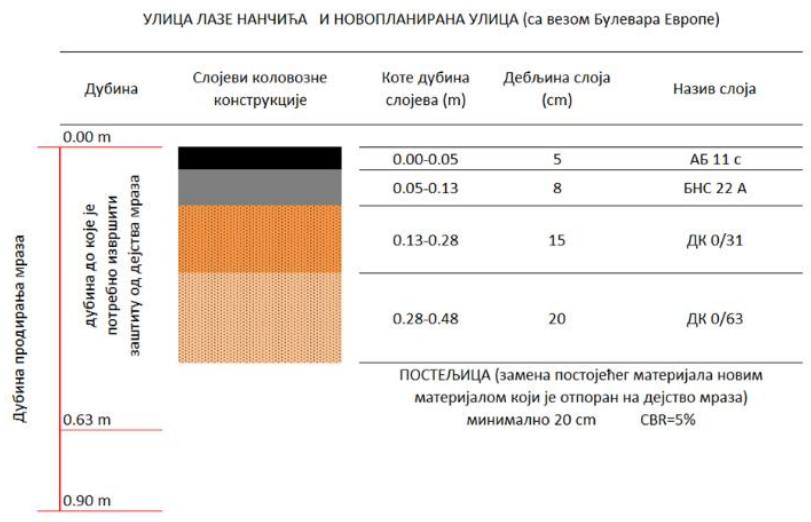

Slika 2. Usvojena kolovozna konstrukcija

\section{REKAPITULACIJA GRAĐEVINSKIH RADOVA}

Za predmetne ulice formiran je predmer i predračun građevinskih radova na osnovu količina koje su sračunate planimetrisanjem ,kroz programski paket „Plateia“. U tabeli 3 prikazana je rekapitulacija građevinskih radova.

Tabela 3. Rekapitulacija građevinskih radova

\begin{tabular}{|c|c|c|c|}
\hline \multicolumn{4}{|c|}{ РЕКАПИТУЛАЦИЈА } \\
\hline & & & \\
\hline \multicolumn{4}{|c|}{$\begin{array}{c}\text { Cаобра ајне површине са пратећом инфраструктуром у улици Лазе Нанчића, делу Булевара } \\
\text { Европе и новопланираној улици (са везом Булевара Европе) у Новом Саду }\end{array}$} \\
\hline 1 & ПРЕПРЕМНИ РАДОВИ & & $20,023,545.00 \mathrm{Din}$ \\
\hline 2 & ЗЕМЉАНИ РАДОВИ & & $16,585,481.60 \mathrm{Din}$ \\
\hline 3 & КОЛОВОЗНА КОНСТРУКЦИЈА & & $52,912,736.00 \mathrm{Din}$ \\
\hline \multirow[t]{2}{*}{4} & ОДВОДЊАВАҢЕ & & $315,000.00 \mathrm{Din}$ \\
\hline & & Укупно: & $89,836,762.60 \mathrm{Din}$ \\
\hline
\end{tabular}

\section{ZAKLJUČAK}

Funkcije saobraćajnica su od fundamentalnog značaja za njihovo planiranje, projektovanje, izvođenje i eksploataciju. Ovim radom obuhvaćen je proces terenskog i laboratorijskog ispitivanja, sa analizom rezultata na osnovu koga je sproveden kompletan tok projektovanja saobraćajnica i pratećih površina sa dimenzionisanjem i usvajanjem kolovozne konstrukcije prema standardu SRPS U C4.015.

$\mathrm{Na}$ ovaj način obezbeđena je procedura za izbor parametara saobraćajnica sa najpovoljnijim funkcionalnim, bezbednosnim i estetskim karakteristikama.

\section{LITERATURA}

[1] Anđus V, Maletin M, Metodologija planiranja i projektovanja puteva- Značajan segment održivog razvoja Srbije, zbornik radova IAUS 1954-2004 Beograd, decembar 2004.

[2] Uzelac Đ. , Kolovozne konstrukcije, FTN Izdavaštvo, Novi Sad, 2015

[3] Satelitski snimak predmetnih ulica, preuzeto sa:https://www.google.com/maps/place/\%D0\%9B\%D0 $\% \mathrm{~B} 0 \% \mathrm{D} 0 \% \mathrm{~B} 7 \% \mathrm{D} 0 \% \mathrm{~B} 5+\% \mathrm{D} 0 \% 9 \mathrm{D} \% \mathrm{D} 0 \% \mathrm{~B} 0 \% \mathrm{D} 0 \% \mathrm{~B}$ D\%D1\%87\%D0\%B8\%D1\%9B\%D0\%B0,+\%D0\%9D\% D0\%BE\%D0\%B2\%D0\%B8+\%D0\%A1\%D0\%B0\%D0 \%B4/@45.2470913,19.8253543,16z/data=!4m5!3m4!1s 0x475b1037527edaa7:0x1a7ccda189c2e5b0!8m2!3d45. $\underline{2472771 ! 4 d 19.8211116}$, datum pristupa 15.06.2021.

\section{Kratka biografija:}

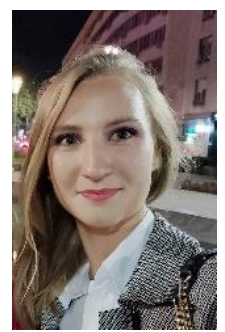

Milica Tepavac rođena je u Somboru 1994. god. Osnovne akademske studije iz oblasti građevinarstva upisuje 2013. godine, a diplomski rad iz predmeta Kolovozne konstrukcije brani u junu 2018. godine i upisuje master studije- smer Putevi, železnice, aerodromi. Master rad na Fakultetu tehničkih nauka iz predmeta Kolovozne konstrukcije odbranila je 2021. godine. 